\title{
Research on Combination of Swing Wing with Canard and Tail used in Fighter Aircraft
}

\author{
Praveen babu, Swathi P Shetty, Kavya G Achar, Steve JohnsonLobo, Lokesh K S, Jagadeesh
}

\begin{abstract}
The present work discloses the new design of a fighter aircraft. Better performance of a fighter in the combat as well in its ground activities is the main vision of our work. It is concentrating on the aircraft short distance take off and landing, stalling controlling, as well as different maneuverings of the aircraft. Many fighter aircraft are having its own working parameters and configurations. Every aircraft shown its own characteristics in flight like maneuverings, stalling etc.The major problem of them is prohibiting some of these characteristics in some angle of attack. So to control we have implemented some modifications. To achieve all these characteristics, we have selected the combination of swing wing with canard and tail configuration. By using this technology we can increase the flight ability to its maximum. So all the characteristics are in the control as we have designed.
\end{abstract}

Keywords:

\section{INTRODUCTION}

Wing sweep is used primarily to reduce the adverse effect of transonic and supersonic flow theoretically shock formation on a swept. The wing sweep and aspect ratio together have a strong effect on the wing alone pitch up characteristics pitch up is the highly undesirable tendency of some aircraft upon reaching an angle of attack the aircraft continuous pitching up until it stalls and departs totally out of control. The exact wing sweep required to provide the desired critical mach no depends on the selected airfoil thickness ratio, taper ratio and the other factors for initial wing layout the trend line. For high speed flight swept wing is desirable for cruise as well as take off and loading, and swept wing is desirable and wing of variable sweep would offer the best of the world. The plane form for a variable sweep aircraft should be developed in the un swept position and then swept to the desired leading edge. Controlling the balance of the variable swept aircraft is a major design problem when the wing sweeps after the aerodynamic center moves with it, the centre of gravity also moves due to wing movement but not nearly as much as aerodynamic center.

Revised Manuscript Received on July 10, 2019.

Praveen babu, UG Scholar, Department of Aeronautical Engineering, Srinivas institute of Technology, Valachil, Mangaluru, Karnataka India. (Email; lbharani79@gmail.com)

Swathi P Shetty, UG Scholar, Department of Aeronautical Engineering, Srinivas institute of Technology, Valachil, Mangaluru, Karnataka India.

Kavya G Achar, UG Scholar, Department of Aeronautical Engineering, Srinivas institute of Technology, Valachil, Mangaluru, Karnataka India.

Steve JohnsonLobo, UG Scholar, Department of Aeronautical Engineering, Srinivas institute of Technology, Valachil, Mangaluru, Karnataka India.

Lokesh K S, Assistant Professor, Department of Mechanical \& Aeronautical Engineering, Srinivas institute of Technology, Valachil, Mangaluru, and Karnataka India.

Jagadeesh, Assistant Professor, Department of Mechanical \& Aeronautical Engineering, Srinivas institute of Technology, Valachil, Mangaluru, and Karnataka India.
To balance the aircraft, either fuel must be pumped to move the centre of gravity or the tail must provide a tremendous down load[1].

Variable sweep aircraft typically exhibit a greater rearward shift in aerodynamic center from subsonic to supersonic speed than fixed wing plane form. The first variable sweep design $\mathrm{X}-5$ research vehicle minimized aerodynamic travel by employing a rail carriage system to provide forward translation to the wing at the swept back position. The XF101-1 aircraft, the second variable sweep design, had a forward translation capability that was somewhat less complex and bulky. But it could not independently vary sweep system incorporated an inboard pivot location without the translation features of the earlier experimental aircraft. It suffered from longitudinal stability and large attendant tail down loading during supersonic flight. Subsequent research effort form that an outboard pivot location minimized the stability increased due to wing sweep. A glove vane was also provided for development at higher mach number to further reduce the trim drag and relies tail load [2].

The variable sweep wing allows the pilot to select the correct wing configuration for the plane intended speed. It is useful for those aircraft that are expected to function at both low speed and high speed and for this version it has been used primarily in military aircraft. Advantages are different aerodynamic sweep at different speeds, allowing aspect ratio to be varied in flight. This is helpful when building airplanes have to takeoff from short runway strips [3].

Canard configuration offers today's designer the potential advantage of less rearward aerodynamic center travel than a tail arrangement and wing or canard load sharing. A designer can adopt the canard to reduce the main wing loading to better control. The main wing flow can be controlled by its flow and aircraft's maneuverability, especially at high angle of attack or during stall. At high angle of attack, surface directs the airflow downward over wing reducing turbulence. It also acts as secondary wing in some critical maneuvering problems. It can also store fuel in the solid structure. It creates high velocity at short distance helping the aircraft to take off in short distance [4].

The dual wing aircraft consistently had higher L/D ratios than the baseline.This was due to a shifting of the two dimensional drag bucket to higher liftcoefficient values thereby permitting higher cruise lift coefficients for thesame two dimensional drag. The induced drag of the dual wing was also belowthat of the baseline with the dual wing having the highest span efficiency of all the configurations.

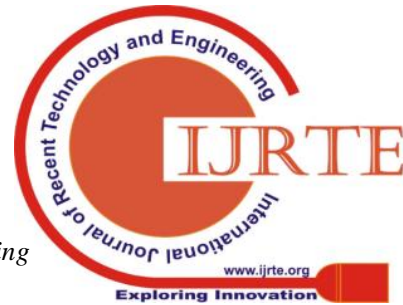




\section{RESEARCH ON COMBINATION OF SWING WING WITH CANARD AND TAIL USED IN FIGHTER AIRCRAFT}

The dual wing was penalized because it had to operateat Reynolds numbers that were almost an order of magnitude below the designairfoil Reynolds number. Operation at higher Reynolds numbers would have allowed two dimensional drag results that are below the single airfoil, at twicethe Reynolds number for a wide range of lift coefficients. Also if the dual wingconfiguration had used airfoils designedfor the dual airfoil mode of operation, the L/D ratios would also have been higher ${ }^{[5]}$.

\section{METHODOLOGY}

The design specification work starts from the nose and ends in tail. The nose cone will be of $45^{0}$ in the front. Hence there will be a formation of the shock cone in which canard and wing stands. The canard, it is a completely different configuration, which serves as a secondary wing as well as high lift device and pitching device. Canard is positioned after the cockpit as the pilot visibility at an angle of $30^{\circ}$ to $45^{0}$ swept back which helps in installing by mixing the main wing flow with its flow. Also the canard only stalls first and after leading to wing. Canard always exhibits its own character of drag reduction. Canard size always is the first for the better performance. Higher the aspect ratio lowers the induced drag. The main advantage is mixing of the wing flow with its flow. As the convenience of the pilot there will be positioning of the canard. That is placed so as to balance the aircraft with variation in the CG and AC. The canard is fixed in the $1 / 4^{\text {th }}$ of the total length of the aircraft next that of the cockpit. Canard is $25 \%$ of the wing approximations which is majorly using for the lifting and controlling. Airfoil of the canard is $6 \%(\mathrm{t} / \mathrm{c})$ to control the stalling. The canard is weighing about $3 \%$ of the total weight of the aircraft and aspect ratio is of $30 \%$ of the wing. Aerodynamic centre of the canard is of $0.4 \mathrm{c}$ as of the supersonic condition.

Swing wing geometry is somewhat same as that of the f14. The airfoil is the series of NACA 64A209.64 mod root and NACA 64A208.91 mod tip. Aerodynamic center of the wing shift from $0.25 \mathrm{c}$ to $0.4 \mathrm{c}$ from subsonic to supersonic. The weight of wing is $15 \%$ of the total weight of the aircraft. Thickness of the airfoil is about $9 \%(\mathrm{t} / \mathrm{c})$ and dihedral angle is $0^{\circ}$.

There is a use of new technology of controlling and swing mechanism. Weight reduction is the main concept in the swinging mechanism. So we also concentrated on the shifting of the center of gravity and aerodynamic center. For the stability of the aircraft we are decreasing the wing load by shifting the fuel from wing to other parts of the aircraft. In this configuration wing swings from $20^{\circ}$ to $69^{\circ}$ as there is a translation from subsonic to supersonic.

Tail helps in very different condition like stalling. In stalling canard stalls first since the pitching is not complete. To maintain the stability of the aircraft tail is compulsory for a air superiority fighter. In this design horizontal tails are fixed, hence we also can shift the fuel from the wing to tail. Tails are positioned in such a way that which matches with the wing edges when the wing is swept back to its maximum. Aspect ratio is about 3 and it is tapered about 0.4 of root for the horizontal tail. The vertical tail is $35^{\circ}$ swept outward and having aspect ratio 1.4 and tapper ratio of 0.2 .

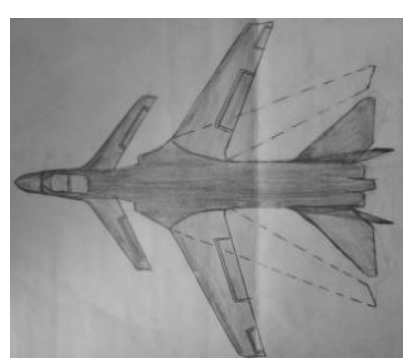

General characteristics

- Crew: 2

- Length: $22.5 \mathrm{~m}$

- Wing span: $19.5 \mathrm{~m}$ at $20^{\circ}$ wing sweep, $11.54 \mathrm{~m}$ at $69^{\circ}$ wing sweep

- Height: $5.95 \mathrm{~m}(19.5 \mathrm{ft})$

- Wing area: $54.5 \mathrm{~m} 2$ and $93.6 \mathrm{~m} 2$

- Empty weight: $18000 \mathrm{~kg}$

- Loadedweight:28282.54kg

- Max.takeoff weight:32000 kg. (approx)

- Powerplant:2× f110-GE-129 after burning turbofan

- Dry thrust: $73.8 \mathrm{kN}(16,610 \mathrm{lbf})$ each

- Thrustwith afterburn: $131 \mathrm{kN}$ each

\section{Performance}

- Maximum speed: Mach 2.4 at 9,000 m (30,000 ft) altitude

- Range: $1,800 \mathrm{~km}$ for typical combat mission

- Ferry range: $3,890 \mathrm{~km}$

- Thrust/weight: 0.9

\section{RESULTS AND DISCUSSIONS}

Canard configuration is mainly using for the multirole supersonic navy tactical aircraft Canard mixes main wing flow with its flow in critical angle of attack. Canard stalls first in the aircraft. So that, it is better in the control of wing stalling. Canard also produces high L/D in short distance of takeoff. It is helping in maneuvering at high angle of attack and stalling, lift and control. At high angle of attack canard surface direct the airflow downward over the wing reducing turbulence. Fore plane creates upper vortex which attaches to the upper surface of the wing stabilizer and re-arranging the airflow over the wing and pressurizing the stall. It's aspect ratio which reduces the inducing drag. It is also acting as the secondary wing in some critical maneuvering problem. Canard is also using as the part of fuel storage.

Swing wing helps in changing of aspect ratio for different speeds. Swing wing is mainly done for the diverse mission requirement of a carrier based fighter and attacker design. $\mathrm{L} / \mathrm{D}$ also varies as the wing swings. This translation helps in short distance takeoff and landing. The Design suit the carrier with limited weight. Fuel capacity is increased because of the multiple storage options. Tail helps in pitching of the aircraft at stalling and also helps in fuel storage. 


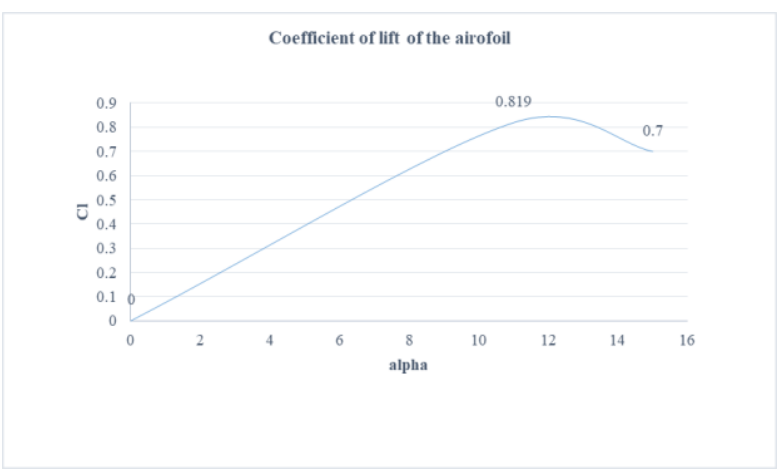

Fig.3 Coefficient of lift of airfoil

Airfoil :NACA 64A209

Max Cl:0.819 Max $\mathrm{Cl} / \mathrm{Cd}: 32$ at $4.5^{\circ}$

Max thickness:9\%at 40\% cord

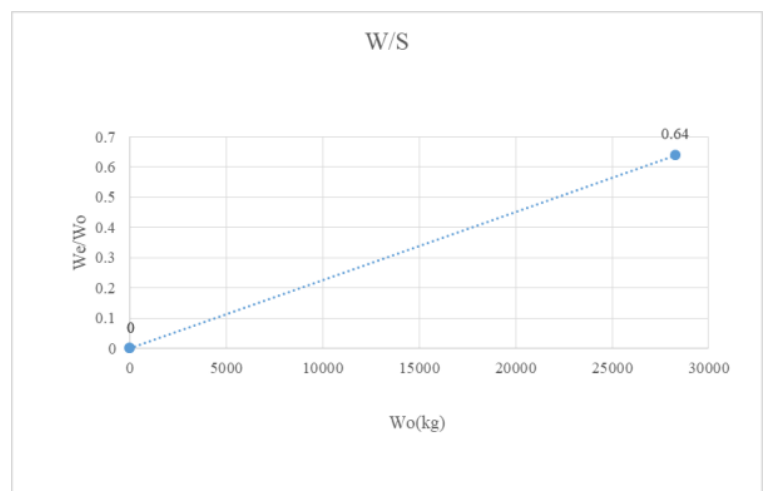

Fig . 4 Weight/area fraction of the aircraft

Wo :28282 kg We/Wo:0.64

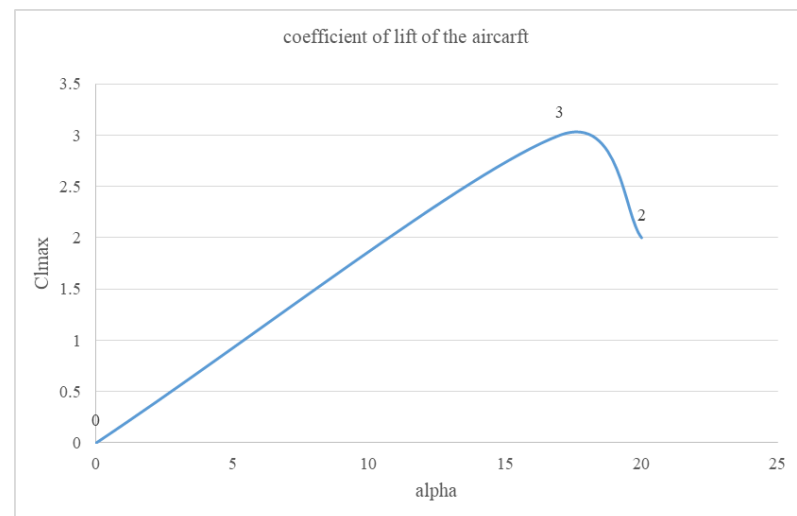

Fig .5 Coefficient of the lift of the aircraft

Clmax : 3 (for STOL aircraft)

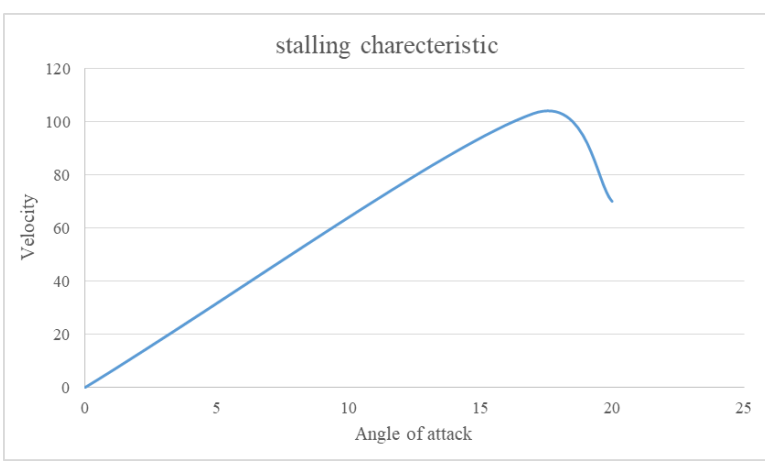

Fig .6 Stalling velocity with respect to angle of attack Vstall: $103 \mathrm{~m} / \mathrm{sec}(338 \mathrm{ft} / \mathrm{sec}$ for STOL) At $17 \mathrm{o}$ of AOA

The above mentioned figures are the results of the aircraft performance. In all kind of aircraft airfoil plays the major role in the lift production as well as the thickness on the stalling. Fig.3 shows the NACA 64A209 airfoil coefficient of lift with respect to angle of attack. The airfoil having Max $\mathrm{Cl}: 0.819$, Max $\mathrm{Cl} / \mathrm{Cd}: 32$ at $4.5^{\circ}$ and max thickness:9\%at $40 \%$ cord. Fig 4 is showing the aircraft weight per area ratio of the aircraft. Loaded weight of the aircraft is $28282 \mathrm{~kg}$ and the We/Wo: 0.64. Fig 5 indicating the maximum coefficient of lift at the lifting of the short distance takeoff and landing. Maximum lift coefficient of the aircraft is 3 and which is at an angle of attack of $17^{\circ}$ and which decreases by increasing angle of attack. Fig 6 is about the Stalling velocity with respect to angle of attack. Stalling speed of the aircraft is $338 \mathrm{ft} / \mathrm{sec}$ at angle of $17^{\circ}$. These above mentioned values are the effective about the work done on the design and on its parameters.

\section{CONCLUSION}

Combination of canard and swing wing configuration, higher lift is produced in the short distance. Canard mixes the main wing flow in the critical angle of attack. Canard and horizontal tails are the solid structures, which helps in the fuel storage as well as in the stalling control.

\section{REFERENCES}

1. “Aircraft design; a conceptual approach" by DANNIEL P RAYMER

2. "Canard/tail comparison for an advanced variable sweep wing fighter" by joseph $\mathrm{p}$.landfield "F-14"grumann

3. Ruthan variEze, designed by Burt Ruthan

4. "Aerodynamic study of canard wing,duel wing, and conventional wing systems for general aviation application"; Bruce P. 